\title{
The morphological and molecular
} characterization of Baylisascaris devosi Sprent, 1952 (Ascaridoidea, Nematoda), collected from Pine marten (Martes martes) in Iran

\author{
Meysam Sharifdini ${ }^{1 *}$, Richard A. Heckmann ${ }^{2}$ and Fattaneh Mikaeili ${ }^{3}$
}

\begin{abstract}
Background: Baylisascaris devosi is an intestinal nematode found in several carnivores including fisher, wolverine, Beech marten, American marten and sable in different parts of the world, but this nematode has not been reported from Pine marten. Therefore, this study aimed to identify Baylisascaris isolated from a Pine marten in Iran using morphological and molecular approaches.

Methods: Specimens of B. devosi were collected from one road-killed Pine marten in northern Iran. Morphological features were evaluated using scanning electron microscopy, energy dispersive $x$-ray analysis and ion sectioning. The molecular characterization was carried out using partial Cox1, LSU rDNA and ITS-rDNA genes.

Results: The nematodes isolated from the Pine marten were confirmed to be B. devosi based on the morphological features and the sequence of ribosomal and mitochondrial loci. X-ray scans (EDAX) were completed on gallium cut structures (papillae, eggs, male spike and mouth denticles) of B. devosi using a dual-beam scanning electron microscope. The male spike and mouth denticles had a high level of hardening elements $(C a, P, S)$, helping to explain the chemical nature and morphology of the worm. Based on these genetic marker analyses, our sequence had the greatest similarity with Russian B. devosi isolated from sable.

Conclusions: In this study, to our knowledge, the occurrence of B. devosi infection in Pine marten is reported for the first time. Molecular analysis showed that these three genes are suitable molecular markers for identification and inferring phylogenetic relationships of Baylisascaris species. Furthermore, the high divergence of Cox 1 between Baylisascaris species indicates that Cox 1 could be used for their phylogenetic and taxonomic studies.
\end{abstract}

Keywords: Baylisascaris devosi, Martes martes, Iran, Molecular characterization, SEM, EDAX

*Correspondence: sharifdini@gums.ac.ir; sharifdini5@gmail.com

${ }^{1}$ Department of Medical Parasitology and Mycology, School of Medicine, Guilan University of Medical Sciences, Rasht, Iran

Full list of author information is available at the end of the article

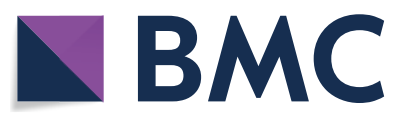

(c) The Author(s) 2021. This article is licensed under a Creative Commons Attribution 4.0 International License, which permits use, sharing, adaptation, distribution and reproduction in any medium or format, as long as you give appropriate credit to the original author(s) and the source, provide a link to the Creative Commons licence, and indicate if changes were made. The images or other third party material in this article are included in the article's Creative Commons licence, unless indicated otherwise in a credit line to the material. If material is not included in the article's Creative Commons licence and your intended use is not permitted by statutory regulation or exceeds the permitted use, you will need to obtain permission directly from the copyright holder. To view a copy of this licence, visit http://creativeco mmons.org/licenses/by/4.0/. The Creative Commons Public Domain Dedication waiver (http://creativecommons.org/publicdomain/ zero/1.0/) applies to the data made available in this article, unless otherwise stated in a credit line to the data. 


\section{Background}

Baylisascaris is a roundworm belonging to the family Ascarididae that has several species, including $B$. procyonis, B. melis, B. transfuga, B. columnaris, B. devosi, B. laevis, B. shroederi, B. venezuelensis and B. potosis. The various species of Baylisascaris have specific definitive hosts and can be identified accordingly [1]. Unembryonated eggs are shed in the feces of the definitive host and become infective in the environment within several weeks. Definitive hosts can be infected by ingesting embryonated eggs from the environment or the consumption of encapsulated third-stage larvae in the muscles of paratenic hosts such as rodents and birds [2]. Human is an accidental host for this parasite, and baylisascariasis in human can be caused by B. procyonis, $B$. columnaris, B. melis, B. devosi, B. transfuga and B. tasmaniensis [3]. Baylisascaris procyonis, the Raccoon roundworm, is the most important species of Baylisascaris and the primary cause of baylisascariasis in human because the larval form is capable of causing severe neurological disease in human. Consequently, the other Baylisascaris species have been less studied compared to B. procyonis [4]. Since baylisascariasis is diagnosed by serological methods and these cannot identify the parasite species, molecular methods are useful for the identification of Baylisascaris species [3].

Baylisascaris devosi was first described as a new species of ascaridids from carnivorous mammals such as fisher (Pekania pennant) and Beech marten (Martes foina) such as Ascaris devosi [5]. Kontrimavichus (1963) considered ascaridids of mustelids to be B. devosi Sprent, 1952 [6]. Adult worms of $B$. devosi live in the intestinal tract of carnivorous mammals including fisher, wolverine (Gulo gulo), Beech marten, sables (Martes zibellina) and American marten (Martes americana) [5, 7].

The different species of Baylisascaris can be distinguished from each other based on morphological features, but since the morphological identification of Baylisascaris species is difficult, especially at the egg, larval and immature worm stages, molecular methods have been used for accurate identification. For the first time, $B$. devosi isolated from wolverine was identified using a molecular method along with the morphological technique, and the study suggested that both morphological and molecular methods are needed for accurate identification of Baylisascaris species [8]. In the other study, B. devosi nematodes collected from Kamchatka sables were identified based on morphological characteristics, and the molecular method was used to confirm their morphology-based identification [9]. In this study, for the first time to our knowledge, $B$. devosi has been isolated from Pine marten (Martes martes) in Iran; therefore, the current study was performed on identification of Baylisascaris based on morphological and molecular approaches. Furthermore, chemical analysis of structures of $B$. devosi was carried out using energy-dispersive $\mathrm{x}$-ray analysis for the first time to our knowledge.

\section{Methods \\ Collections}

Seven adult nematodes, including four female worms and three male worms, were collected from one roadkilled Pine marten in Ramsar district $\left(36^{\circ} 47^{\prime} \mathrm{N}, 50^{\circ} 35^{\prime} \mathrm{E}\right)$, Mazanderan Province, northern Iran, in August 2019. The animal was an adult male weighing $1700 \mathrm{~g}$, and morphometric measurements were: body length $=47 \mathrm{~cm}$; tail length $=25 \mathrm{~cm}$; shoulder height $=19 \mathrm{~cm}$. A comprehensive autopsy was performed, and only the specimens of ascarid nematodes were collected from the intestine. The recovered worms were washed extensively in physiological saline. Two specimens were fixed in $70 \%(\mathrm{v} / \mathrm{v})$ ethanol for transport to Brigham Young University in Utah, USA, for scanning electron microscopy (SEM) studies, metal analysis and gallium (Ga) sections. Also, two specimens were preserved in $70 \%$ ethanol until extraction of genomic DNA for molecular study.

\section{SEM (scanning electron microscopy)}

Specimens that had been fixed and stored in $70 \%$ ethanol were processed for scanning electron microscopy (SEM) following standard methods [10]. These included critical point drying (CPD) in sample baskets and mounting on SEM sample mounts (stubs) using conductive doublesided carbon tape. Samples were coated with gold and palladium for 3 min using a Polaron \#3500 sputter coater (Quorum (Q150 TES; www.quorumtech.com) establishing an approximate thickness of $20 \mathrm{~nm}$. Samples were placed and observed in an FEI Helios Dual Beam Nanolab 600 (FEI, Hillsboro. Oregon) scanning electron microscope with digital images obtained in the Nanolab software system (FEI, Hillsboro, OR) and then transferred to a USB for future reference. Samples were received under low vacuum conditions using $10 \mathrm{KV}$, spot size 2, 0.7 Torr, using a GSE detector.

\section{Energy-dispersive x-ray analysis}

Standard methods were used for preparation similar to the SEM procedure. Specimens were examined and positioned with the above SEM instrument, which was equipped with a Phoenix energy-dispersive $\mathrm{x}$-ray analyzer (FEI, Hillsboro, OR). X-ray spot analysis and live scan analysis were performed at $16 \mathrm{Kv}$ with a spot size of 5 , and results were recorded on charts and stored with digital imaging software attached to a computer. The TEAM (Texture and Elemental Analytical Microscopy) software system (FEI, Hillsboro, OR) was used. Data were 
stored on a USB for future analysis. The data included weight percent and atom percent of the detected elements following correction factors.

\section{Ion sectioning}

A dual-beam SEM with a gallium (Ga) ion source (GIS) is used for the LIMS (liquid ion metal source) part of the process. The structures (male spike, papillae, egg and mouth denticles) of the worm were centered on the SEM stage and cross sectioned using a probe current between $0.2 \mathrm{nA}$ and $2.1 \mathrm{nA}$ according to the rate at which the area was cut. The time of cutting is based on the nature and sensitivity of the tissue. Following the initial cut, the sample also underwent a milling process to obtain a smooth surface. The cut was then analyzed with an $\mathrm{x}$-ray for chemical ions with an electron beam (Tungsten) to obtain an x-ray spectrum. Results were stored with the attached imaging software. The intensity of the Ga beam was variable according to the nature of the material being cut.

\section{DNA extraction and PCR amplification}

For DNA extraction, adult worms of $B$. devosi were washed three times in distilled water to remove ethanol. Total genomic DNA was extracted using the Qiagen DNeasy tissue kit (Qiagen Inc., Valencia, CA, USA) according to the manufacturer's instructions. Partial mitochondrial cytochrome $\mathrm{c}$ oxidase 1 (Cox1), large subunit ribosomal ribonucleic acid (LSU rDNA) and ITS-rDNA genes were subjected to PCR amplification. The forward primer LCO1490 (5'-GGTCAACAAATC ATAAAGATATTGG-3') and reverse primer $\mathrm{HCO} 2198$ (5'-TAAACTTCAGGGTGACCAAAAAATCA-3') were used to amplify an about 700 bp fragment of the Cox 1 gene [11]; the forward primer LSU391 (5'- AGCGGA GGAAAAGAAACTAA- $3^{\prime}$ ) and reverse primer LSU501 (5'-TCGGAAGGAACCAGCTACTA- 3') were used for the amplification of a $1100 \mathrm{bp}$ fragment of the D2D3 expansion segment of LSU rDNA [12]. Also, a 1050-bplong amplicon containing partial $18 \mathrm{~S}$ rDNA, complete ITS1, 5.8S and partial ITS2 rDNA was amplified using the forward primer Vrain_F (5' TTGATTACGTCCCTG CCCTTT- $\left.3^{\prime}\right)$ and the reverse primer AB28 (5' ATATGC TTAAGTTCAGCGGGT-3') [13, 14]. All PCR reactions were carried out in a $30 \mu \mathrm{l}$ reaction mix, containing $15 \mu \mathrm{l}$ of PCR premix (2x Master Mix RED Ampliqon, Odense, Denmark), 20 pmol of each primer and $2 \mu$ of template DNA. The temperature profile was one initial denaturation cycle at $95{ }^{\circ} \mathrm{C}$ for $4 \mathrm{~min}$ followed by 35 cycles of denaturation at $94{ }^{\circ} \mathrm{C}$ for $30 \mathrm{~s}$, annealing at $55{ }^{\circ} \mathrm{C}$ for $30 \mathrm{~s}$ (for Cox 1), $49{ }^{\circ} \mathrm{C}$ for $30 \mathrm{~s}$ (for LSU rDNA) and $52{ }^{\circ} \mathrm{C}$ for $35 \mathrm{~s}$ (for ITS-rDNA) and extended at $72{ }^{\circ} \mathrm{C}$ for $1 \mathrm{~min}$, with a final extension step at $72{ }^{\circ} \mathrm{C}$ for $5 \mathrm{~min}$. A sample containing water instead of template DNA was included in each run as a negative control.

The PCR products were separated by electrophoresis on a $1.5 \%$ agarose gel and visualized using a UV transluminator (Vilber Lourmat, Collégien, France). The amplification products were sequenced on an ABI 3730 automatic sequencer (Applied Biosystems, Foster City, CA, USA) in both directions, using the same PCR primers as used in the PCR.

The sequence results were edited and trimmed using Chromas v.2.01 and Geneious software (www.geneious. com). The basic local alignment search tool (BLAST) program (http://www.ncbi.nlm.nih.gov/blast/) was used to compare the consensus sequences with GenBank references sequences. The sequences obtained in this study were deposited in the GenBank database (accession numbers: MN960313 for the partial LSU rDNA; MN961617 for the partial Cox1 gene; MN960312 for the ITS-rDNA gene).

\section{Phylogenetic analysis}

Phylogenetic trees were constructed with sequences obtained in the present study along with reference sequences deposited in GenBank using the maximum likelihood (ML) method and Tamura-3 parameter model, and genetic distances were calculated with the maximum composite likelihood model in MEGA6 software (http:// www.megasoftware.net/). The reliabilities of the phylogenetic trees were assessed using the bootstrap value with 1000 replications. The sequences used for the phylogenetic analysis are listed in Table 1.

\section{Results \\ Morphological}

The body length of male and female worms was 6.5-12 $\mathrm{cm}(n=3)$ and $8-16 \mathrm{~cm}(n=4)$, respectively. Observation with the scanning electron microscope showed that the triangular mouth of $B$. devosi was surrounded by three lips; one of the lips was located in dorsal position and the other two in the ventral position (Fig. 1a, b). There was a pair of sensory papillae on the lateral margin of the lips, and the inner face of the free edge of each lip was armed with small denticles (Fig. 1c-f). The male posterior end showed the presence of pre- and post-cloacal papillae that scattered on the sub-ventral part. The total count of pre-cloacal papillae was 28 pairs. There were four pairs of post-cloacal genital papillae (Fig. 2a); the first and second pairs were double but the third and fourth pairs were single (Fig. 2a, b). There were cuticular structures around the cloacal opening in the male worm (Fig. 2c). Also, a small distinct spike was present on the posterior end of the tail (Fig. 2d-f). In the female worms, the vulvar opening was situated in the anterior half of the body length. 
Table 1. Geographic origin, host, accession numbers and references of Cox1, LSU rDNA and ITS-rDNA sequences of Baylisascaris species deposited in GenBank

\begin{tabular}{|c|c|c|c|c|c|c|}
\hline Species & Host & $\begin{array}{l}\text { GenBank acc. } \\
\text { no. LSU rDNA }\end{array}$ & GenBank acc. no. ITS rDNA & GenBank acc. no. Cox 1 & Location & References \\
\hline B. devosi & Martes martes & MN960313 & MN960312 & MN961617 & Iran & Current study \\
\hline B. devosi & Pekania pennanti & MG937776 & MH030598 & MH795151 & Canada & [24] \\
\hline B. devosi & Martes zibellina & KY465564 & KY465505 & KX646394 & Russia & [9] \\
\hline B. procyonis & Procyon lotor & $\begin{array}{l}\text { MG937774 and } \\
\text { MG937775 }\end{array}$ & MH030597 & - & USA & [24] \\
\hline B. procyonis & Procyon lotor & AY821774 & - & - & USA & {$[30]$} \\
\hline B. procyonis & Procyon lotor & - & JQ403615 & - & Norway & {$[31]$} \\
\hline B. procyonis & Procyon lotor & - & MH030597 & - & USA & {$[32]$} \\
\hline B. procyonis & Procyon lotor & - & - & $\begin{array}{l}\text { KJ698559, } \\
\text { KJ698566 and } \\
\text { KJ698567 }\end{array}$ & China & Unpublished \\
\hline B. procyonis & Procyon lotor & - & - & JF951366 & China & [26] \\
\hline B. columnaris & Mephitis mephitis & $\begin{array}{l}\text { MG937772 and } \\
\text { MG937773 }\end{array}$ & MH030594 and MH030595 & & USA & [24] \\
\hline B. columnaris & Mephitis mephitis & - & - & $\begin{array}{l}\text { KY580736, } \\
\text { KY580738 and } \\
\text { KY580739 }\end{array}$ & USA & [33] \\
\hline B. transfuga & Ursus americanus & MH551546 & - & - & Canada & {$[32]$} \\
\hline B. transfuga & Ursus americanus & - & MH030602 & - & USA & [24] \\
\hline B. transfuga & Ursus arctos & MG937779 & - & - & Canada & [24] \\
\hline B. transfuga & Ursus maritimus & JN257008 & - & - & China & {$[25]$} \\
\hline B. transfuga & Ursus arctos & KC543471 & - & - & The Netherlands & [34] \\
\hline B. transfuga & $\mathrm{Na}^{\mathrm{a}}$ & - & JN617990 & - & $\mathrm{Na}$ & Unpublished \\
\hline B. transfuga & Thalarctos maritimus & - & HM594951 & & Italy & {$[35]$} \\
\hline B. transfuga & Ursus maritimus & - & - & HQ671079 & China & {$[26]$} \\
\hline B. schroederi & Ailuropoda melanoleuca & JN257013 & - & - & China & {$[25]$} \\
\hline B. schroederi & Ailuropoda melanoleuca & - & - & $\begin{array}{l}\text { KJ587808 and } \\
\text { KJ587837 }\end{array}$ & China & {$[36]$} \\
\hline B. schroederi & Ailuropoda melanoleuca & - & - & HQ671081 & China & {$[27]$} \\
\hline B. ailuri & Ailurus fulgens & JN257012 & - & - & China & [25] \\
\hline B. ailuri & Ailurus fulgens & - & - & HQ671080 & China & {$[27]$} \\
\hline B. tasmaniensis & Sarcophilus harrisii & MG937781 & - & - & Australia & [24] \\
\hline B. tasmaniensis & Sarcophilus harrisii & - & MH030603 & - & Australia & {$[32]$} \\
\hline B. venezuelensis & Tremarctos ornatus & - & $\begin{array}{l}\text { KX151725, KX151726 and } \\
\text { KX151727 }\end{array}$ & - & Venezuela & {$[37]$} \\
\hline
\end{tabular}

a $\mathrm{Na}$, not available

The female anal opening had a smooth surrounding surface without any papillae (Fig. 3a, b). The fertilized eggs were ellipsoidal in shape and covered with minuscule pits (Fig. 3c, d).

Figure $4 \mathrm{a}, \mathrm{b}$ shows high magnification of the male papillae. The male phasmids were situated after the fourth pair of post-cloacal papillae (Fig. 4c, d). Phasmids of the female worm were located on the sub-ventral side of one-third of the posterior part of the tail (Fig. 4e, f).

\section{Energy-dispersive $x$-ray analysis (EDXA)}

Table 2 presents the $x$-ray scan data for the gallium cut structures (male spike, male papillae, mouth denticles and egg) of $B$. devosi. It is a summary of the $\mathrm{x}$-ray spectra given in Figs. 5, 6, 7 and 8. The worm had prominent structures. The three major chemical elements for the hardening of these structures were calcium, sulfur and phosphorus. Representative of these high levels were the denticles in the mouth region (calcium 18.56; sulfur 9.20; phosphorus $6.79 \mathrm{wt} \%$ ). 

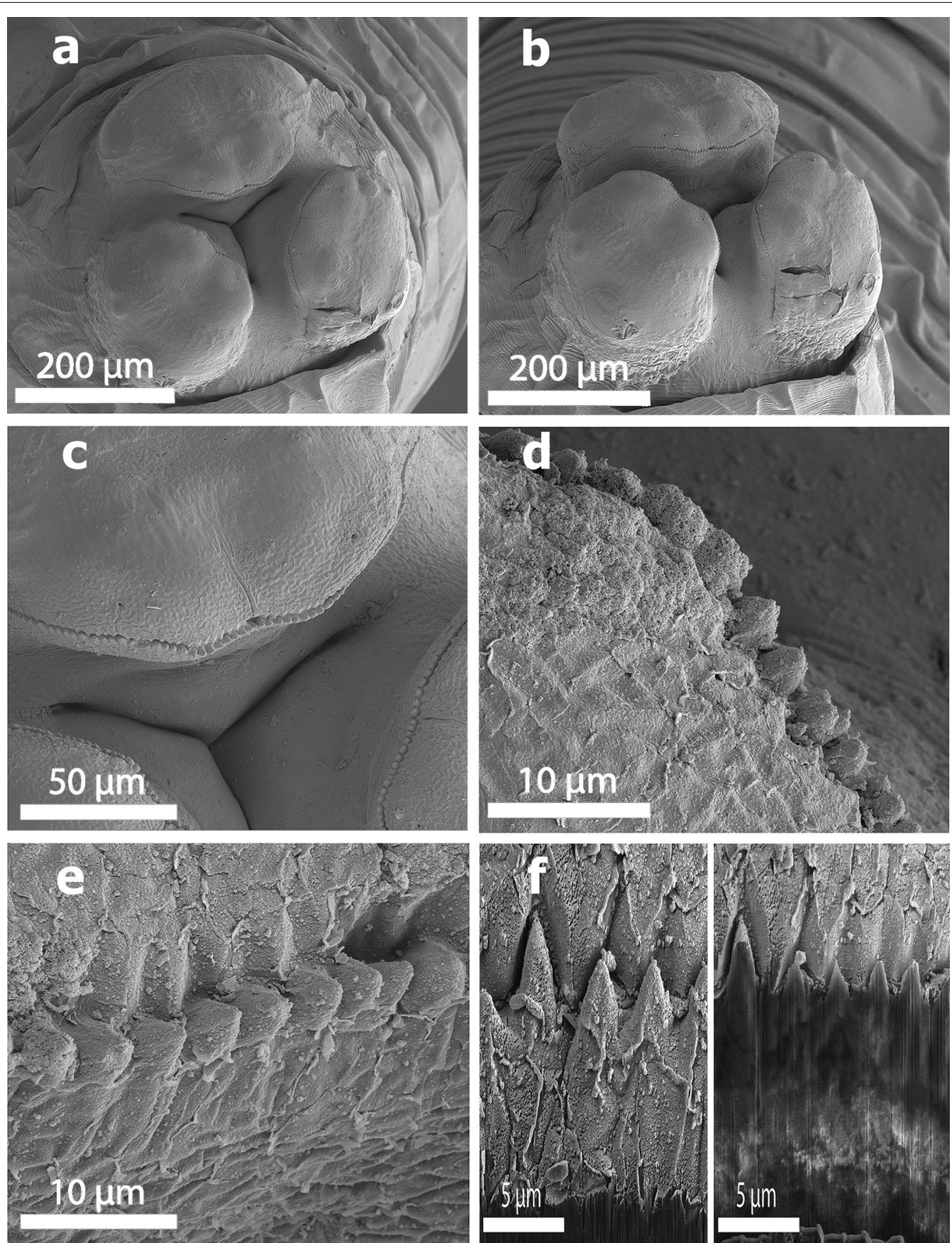

Fig. 1 SEM of specimens of Baylisascaris devosi from Martes martes in Iran. a En face view of the mouth area with the three fleshy lips characteristic of Ascarid worms. $\mathbf{b}$ Lateral view of the mouth entrance for the worm. $\mathbf{c}$ One of the fleshy lips with teeth-like denticles on the surface. $\mathbf{d}$ High magnification of the denticles. $\mathbf{e}$ En face view of the denticles found on both surfaces of the lip. $\mathbf{f}$ Intact and cut denticles (see x-ray print-out of a cut denticle)

\section{Molecular results}

The specimens of $B$. devosi successfully presented amplification of the partial Cox1, LSU rDNA and ITS-rDNA genes. The Cox 1 dataset (679 nt) included 14 sequences for six species of genus Baylisascaris and the sequence of $B$. devosi obtained in the present study. The LSU rDNA dataset (998 nt) included 14 sequences for 7 species of genus Baylisascaris and our sequence of B. devosi. Also, the ITS-rDNA gene dataset (938 nt) included 15 sequences for 7 species of genus Baylisascaris and the 

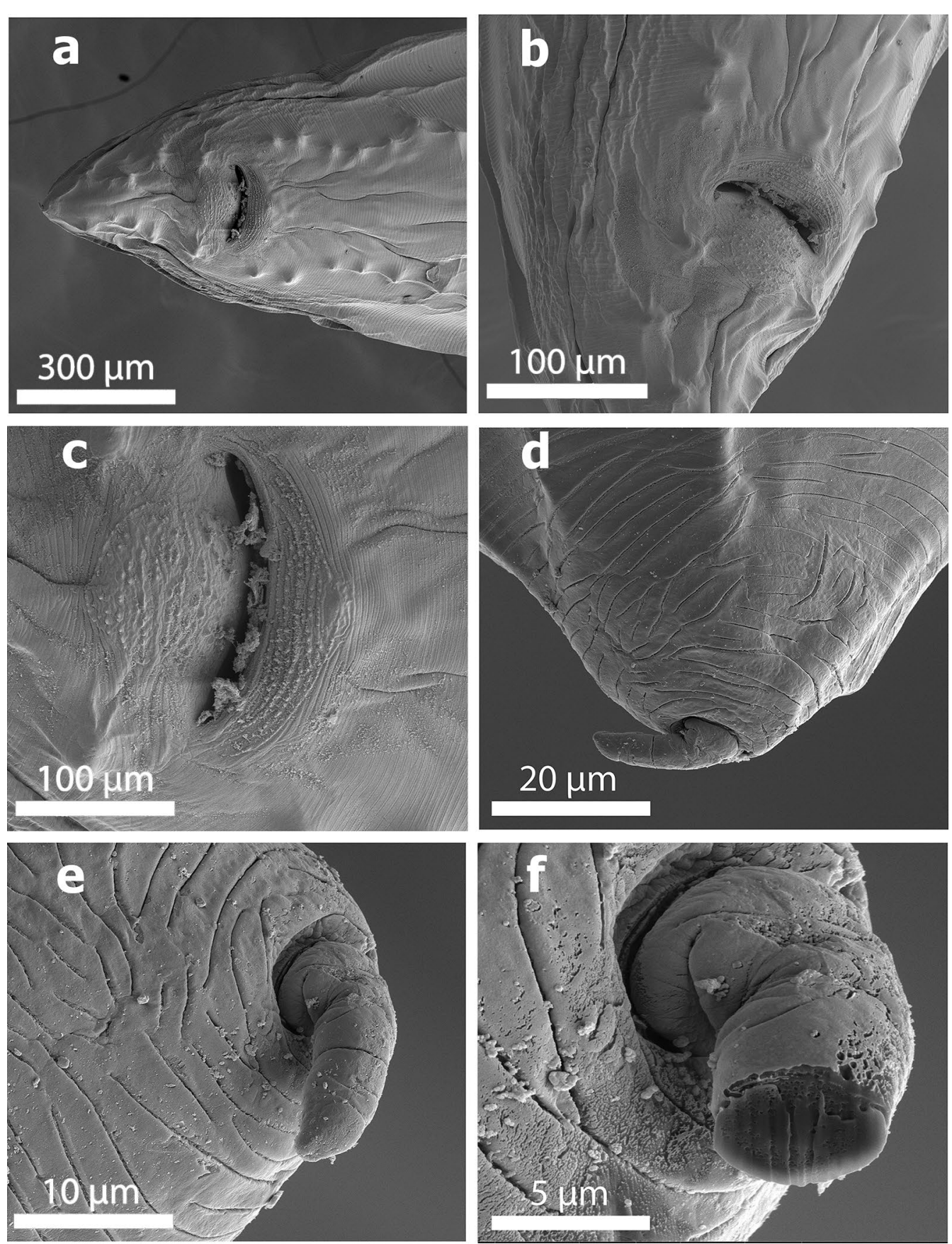

Fig. 2 SEM of specimens of Baylisascaris devosi from Martes martes in Iran. a Cloacal region of the male ascarid worm with numerous papillae, the number of which is a taxonomic key. $\mathbf{b}$ Lateral view of the male ascarid worm with numerous papillae. $\mathbf{c}$ Cuticular structures around the male cloacal opening. $\mathbf{d}$, e A small distinct spike found at the posterior end of the worm. $\mathbf{f}$ Intact and gallium cut of the male spike (see $x$-ray print-out for cut male spike)

sequence of $B$. devosi obtained in this study. Intra-species variation within isolates of $B$. devosi was $0.8-1.4 \%, 0 \%$ and $0-0.2 \%$ for Cox 1 , LSU rDNA and ITS-rDNA fragments, respectively. Inter-generic differences based on the partial Cox 1 sequence between our sequence of $B$. devosi with $B$. procyonis, B. columnaris, B. transfuga, $B$. ailuri and B. schroederi were $4.2-4.7 \%, 4.5-5.3 \%, 8.1 \%$, $9.4 \%$ and $10.3 \%$, respectively. Inter-generic differences based on the partial LSU rDNA sequence between our sequence of $B$. devosi with $B$. procyonis, B. columnaris, 

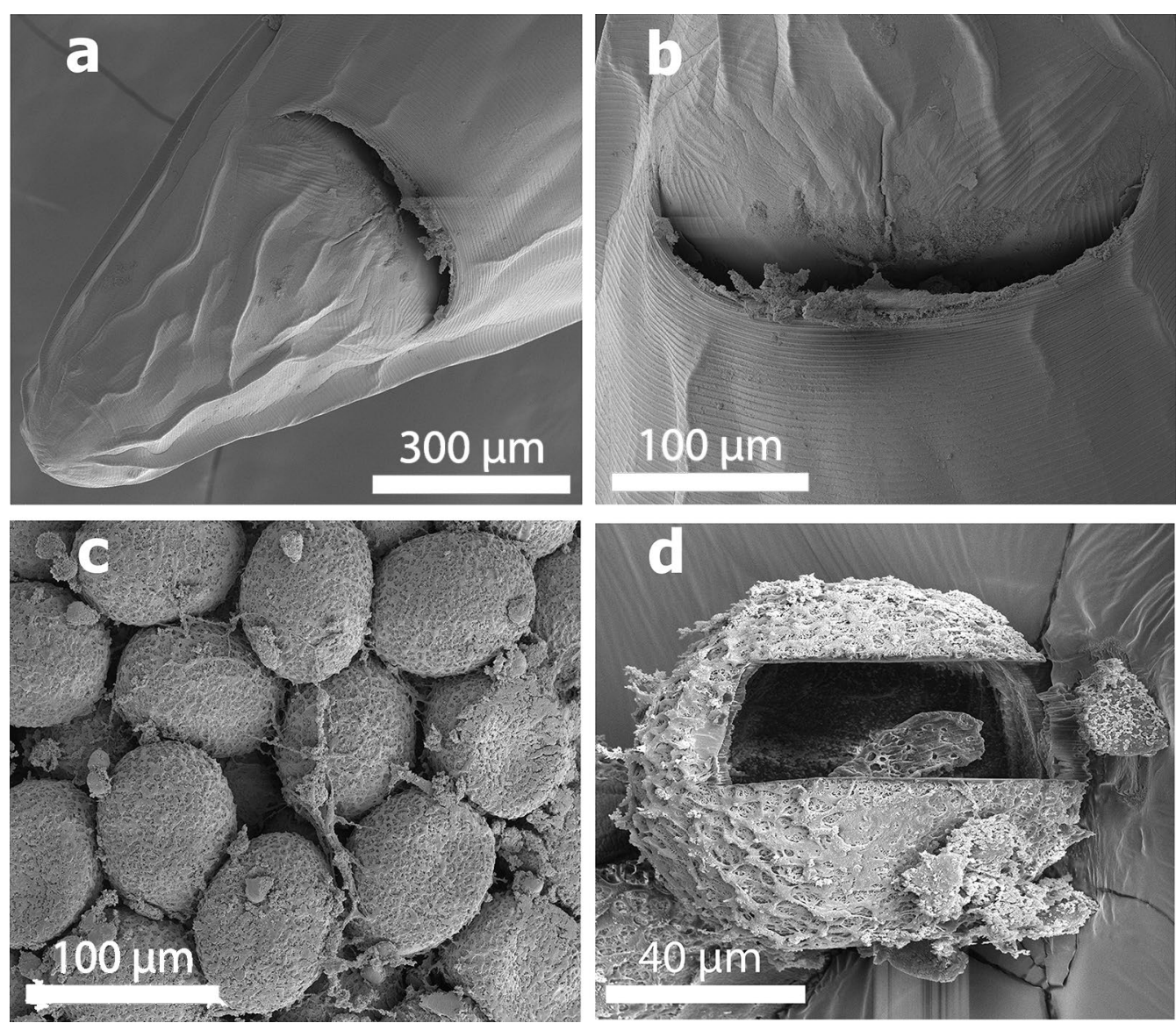

Fig. 3 SEM of specimens of Baylisascaris devosi from Martes martes in Iran. a Posterior view (ventral side) of the female worm with the anal opening. b Smooth surrounding surface of female anal opening. $\mathbf{c}$ Eggs of Baylisascaris devosi. $\mathbf{d}$ Gallium cut egg of the worm (see x-ray print-out of the cut egg)

B. transfuga, B. schroederi, B. ailuri and B. tasmaniensis were $0.9 \%, 1.0 \%, 1.8-2.1 \%, 1.8 \%, 2.1 \%$ and $3.3 \%$, respectively. Also, the sequence divergence based on the partial sequence of ITS-rDNA between $B$. devosi with $B$. procyonis, $B$. columnaris, $B$. venezuelensis, $B$. transfuga, $B$. schroederi and B. tasmaniensis was $1.2 \%, 1.1-1.2 \%, 5.3 \%$, $2.4-2.5 \%, 3.6 \%$ and $3.7 \%$, respectively.

According to phylogenetic analysis based on the Cox 1 gene, our sequence of $B$. devosi (MN961617) was grouped with $B$. devosi (KX646394) isolated from sable in Russia and B. devosi (MH795151) isolated from fisher in Canada with strong support. This clade appeared as a sister group with B. procyonis (KJ698559, KJ698566, JF951366 and KJ698567) and B. columnaris (KY580736, KY580738 and KY580739) with statistical support of $100 \%$. Moreover, B. ailuri (HQ671080), B. transfuga (HQ671079) and B. schroederi (KJ587808, KJ587837 and HQ671081) were located as the sister group of the major clade with high statistical support (Fig. 9).
The phylogenetic analysis based on the LSU rDNA illustrated that the $B$. devosi sequence obtained in this study was grouped with $B$. devosi (MG937776) isolated from fisher in Canada and B. devosi (KY465564) isolated from sable in Russia with high bootstrap values. This clade was located as monophyletic and a sister taxon of B. procyonis (AY821774, MG937774 and MG937775) and B. columnaris (MG937772 and MG937773) with strong support. Indeed, as a major sister group, B. transfuga (MH551546, MG937779, JN257008 and KC543471), B. schroederi (JN257013) and B. ailuri (JN257012) were clustered close to the clade of $B$. devosi, B. procyonis and $B$. columnaris in the tree. The sequence of $B$. tasmaniensis (MG937781) was located at the basal position to the members of genus Baylisascaris (Fig. 10).

The phylogenetic reconstruction based on the partial sequence of ITS-rDNA showed that our sequence of $B$. devosi was clustered with $B$. devosi (KY465505) isolated from sable in Russia and B. devosi (MH030598) isolated 

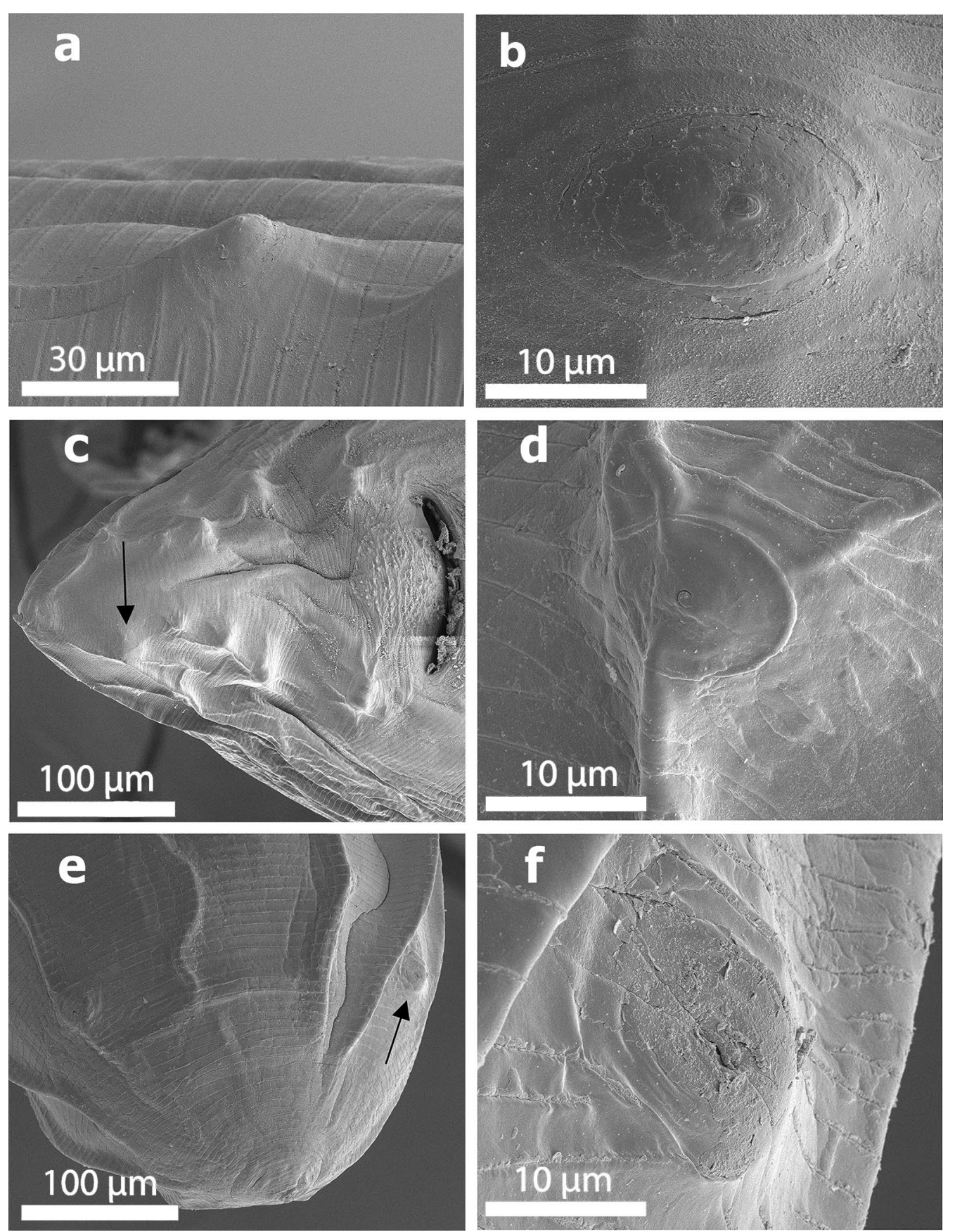

Fig. 4 SEM of specimens of Baylisascaris devosi from Martes martes in Iran. a Lateral view of papillae on the cuticular surface of the male worm. b Enlarged male papillae. c Posterior part ventral side of male showing the phasmids (arrow) and other structures such as papillae. $\mathbf{d}$ High magnification of the phasmid of the male ascarid. e Posterior end of the female showing the phasmids (arrow). $\mathbf{f}$ Phasmid for the female ascarid

from fisher in Canada with high statistical support. This clade appeared to be a sister group consisting of B. procyonis (JQ403615 and MH030597) and B. columnaris (MH030594 and MH030595). These two clades grouped as a sister taxon with B. schroederi (JN210911 and JN210912), B. transfuga (MH030602, JN617990 and HM594951) and B. venezuelensis (KX151725, KX151726 and KX151727). Similar to the LSU rDNA tree, B. tasmaniensis (MG937781) isolate was placed at the basal position to the members of genus Baylisascaris (Fig. 11). 
Table 2. Summary of x-ray scans for Baylisascaris devosi structures that have been cut with a gallium beam (LMIS) and then scanned

\begin{tabular}{lllll}
\hline Chemical elements & \multicolumn{4}{l}{ Baylisascaris devosi } \\
\cline { 2 - 5 } & Male spike & Male papillae & Mouth denticles & Egg \\
\hline Sodium (Na) & 0.15 & 1.37 & 0.24 & 0.12 \\
Magnesium (Mg) & 0.20 & 0.49 & 1.08 & 0.42 \\
Phosphorus (P) & 2.59 & 1.92 & 6.79 & 2.19 \\
Sulfur (S) & 5.07 & 1.39 & 9.20 & 2.52 \\
Potasium (K) & 0.39 & 0.00 & 0.43 & 0.38 \\
Calcium (Ca) & 6.01 & 2.50 & 18.56 & 1.24 \\
\hline
\end{tabular}

Wt $\%$. Common protoplasmic elements omitted $(C, N, O)$ as well as preparation chemicals $(\mathrm{Pd}, \mathrm{Au}, \mathrm{Ga})$

\section{Discussion}

Baylisascaris species are identified according to their morphological features such as the length and width of the adult worm, length of spicules, number of preanal papillae and position of the cervical alae [1]. Adult males of $B$. devosi measure 57 to $123 \mathrm{~mm}$ in length and $1.3 \mathrm{~mm}$ in width, while adult females are $105-285 \mathrm{~mm}$ long and $2.5 \mathrm{~mm}$ wide. The male worms have relatively short and thick spicules $(0.39-0.54 \mathrm{~mm})$, the number of pre-anal papillae ranges from 21 to 40 pairs, and the cervical alae are invisible $[2,5,9,15]$. In this study, the body length of female $(80-160 \mathrm{~mm})$ and male $(65-120$ $\mathrm{mm}$ ) worms was similar to those in the study conducted by Tranbenkova and Spiridonov (2017), who reported the female and male body lengths were $78-168 \mathrm{~mm}$ and

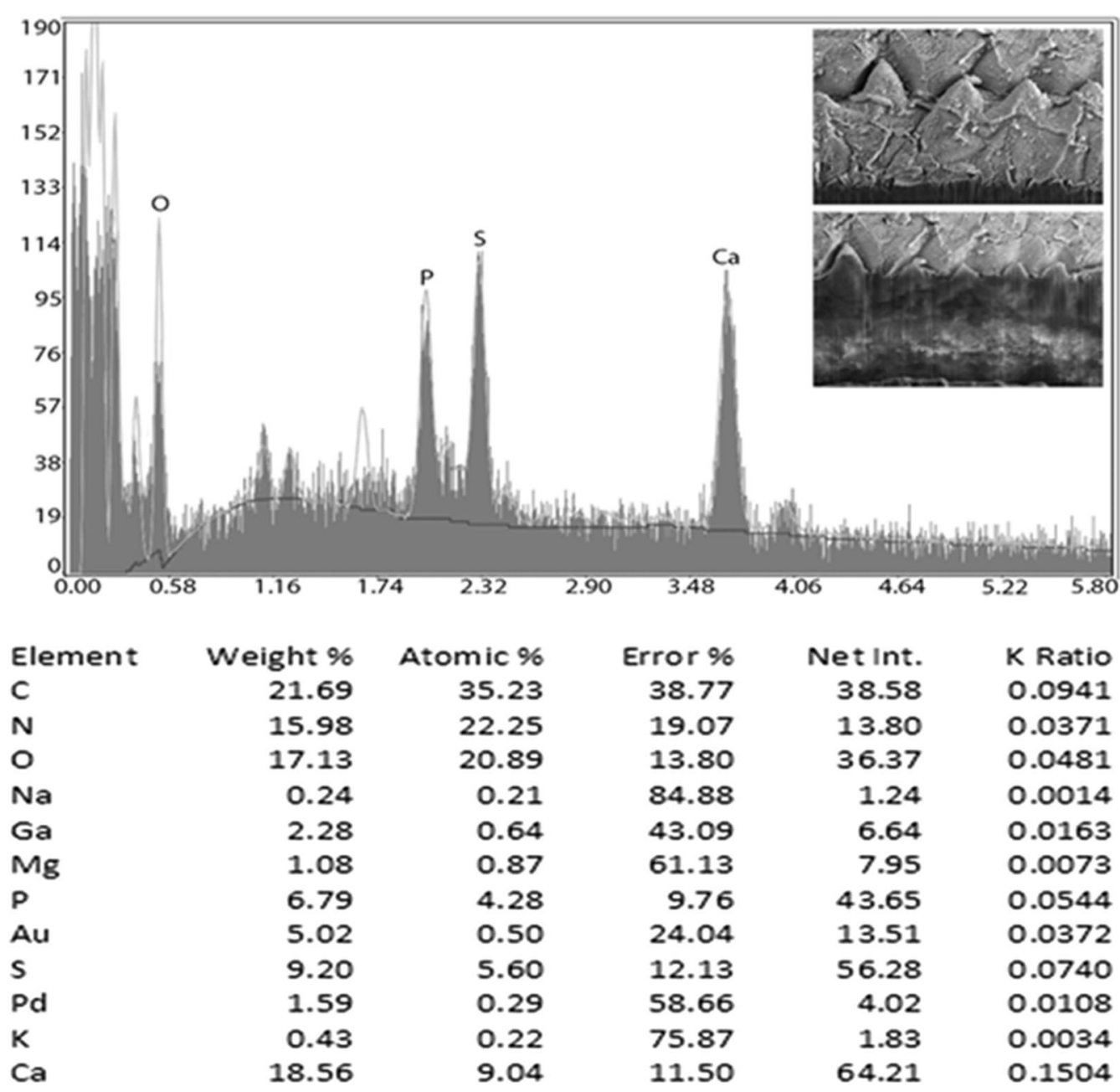

Fig. 5 Energy-dispersive x-ray spectrum for the denticles found on surfaces of the lip of a Baylisascaris devosi specimen showing high levels of calcium, sulfur and phosphorus. Insert: SEM of a gallium cut denticle 


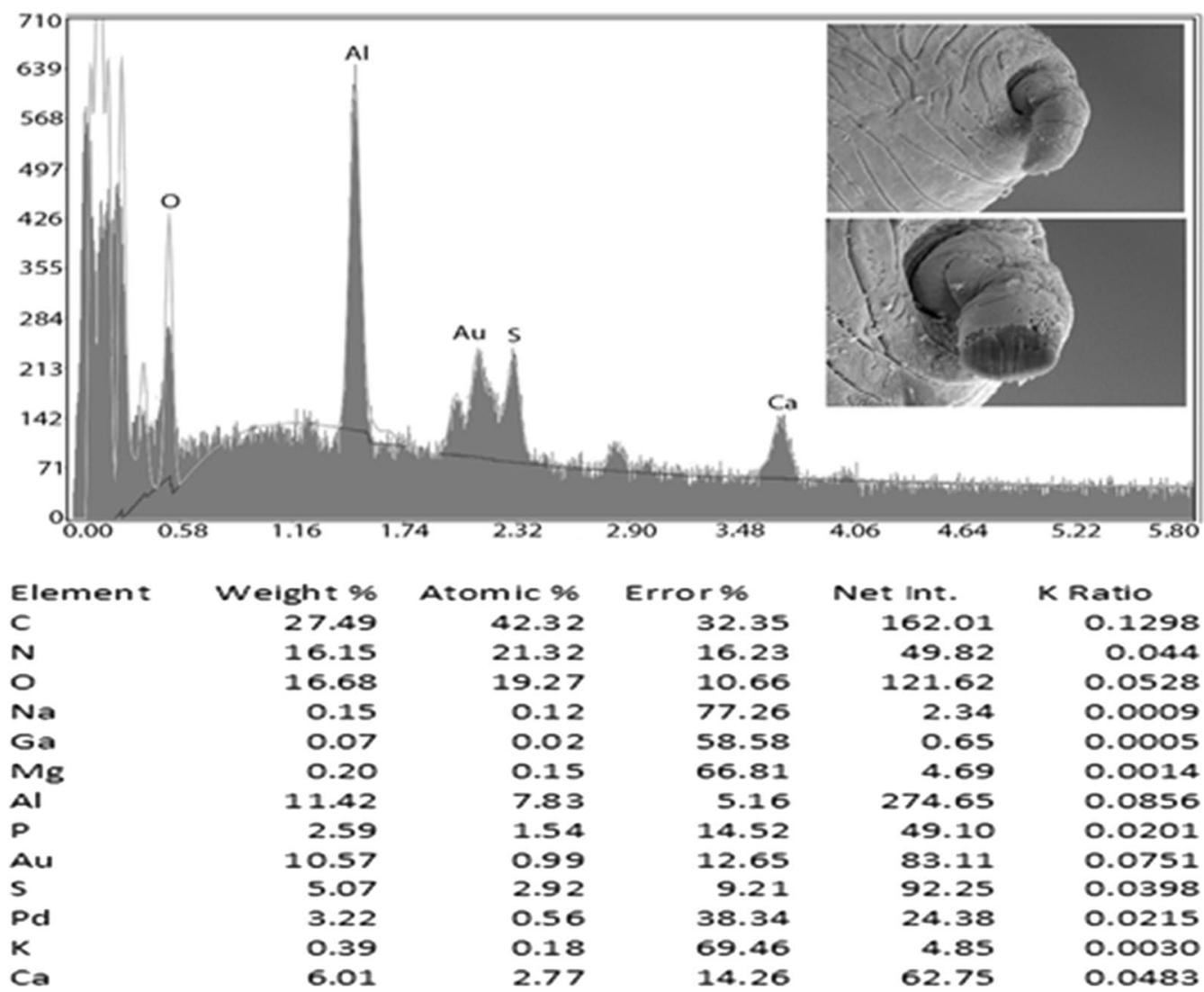

Fig. 6 Energy-dispersive $x$-ray spectrum for the male spike of a Baylisascaris devosi specimen showing high levels of calcium and sulfur. Insert: SEM of a cross gallium cut male spike

58-140 mm, respectively [9]. In our study, a triangular mouth of $B$. devosi surrounded by three lips and armed with small denticles was observed using the scanning electron microscope. Our findings are in agreement with the reports of Tranbenkova and Spiridonov (2017); the results of morphological examination showed that adult worms had three prominent anterior lips with a row of denticles on the lip surface [9]. In the female B. devosi isolated from Pine marten in Iran, the vulvar opening was situated in the anterior half of the body length, and similar to our study, the vulvar opening of the female worm of Russian B. devosi isolated from sable was situated on the border between the first and second quarter of the body length [9]. In this study, the total count of pre-cloacal papillae was around 28 pairs.

One of the major advances in parasite research has been the use of dual-beam scanning electron microscopes and $\mathrm{x}$-ray software (EDXA, energy-dispersive $\mathrm{x}$-ray analysis) [16-19]. The chemical elements of a parasite structure can be determined in minute amounts and then applied to the morphology of the organism. The dual beam allows the researcher to cut the minute structures (such as hooks of acanthocephala) with a gallium beam and analyze the surface [16, 20-23]. Most of the analysis is of a qualitative, not quantitative, nature for the parasites. Often the analysis will relate to parasite nutrition and habitat. The technique may also be useful for taxonomy. Prominent structures of $B$. devosi including eggs, male spikes, mouth denticles and male papillae were cut and analyzed for chemical elements. These structures, with the exception of the eggs and male papillae, had a high level of hardening elements (Ca, P, S), which help explain the chemical nature and morphology of the worm. The cited elements are common in other hardened structures of animals such as the hooks of acanthocephala and mammalian teeth. The listed elements probably form a calcium phosphate apatite.

DNA sequence-based methods have been widely applied over recent years for species identification, classification and evaluation of phylogenetic relationships among ascarid nematodes [24, 25]. Morphological differences between Baylisascaris species are not so clear; therefore, utilization of the sequence data will be helpful in this aspect. Based on the results of the LSU rDNA 


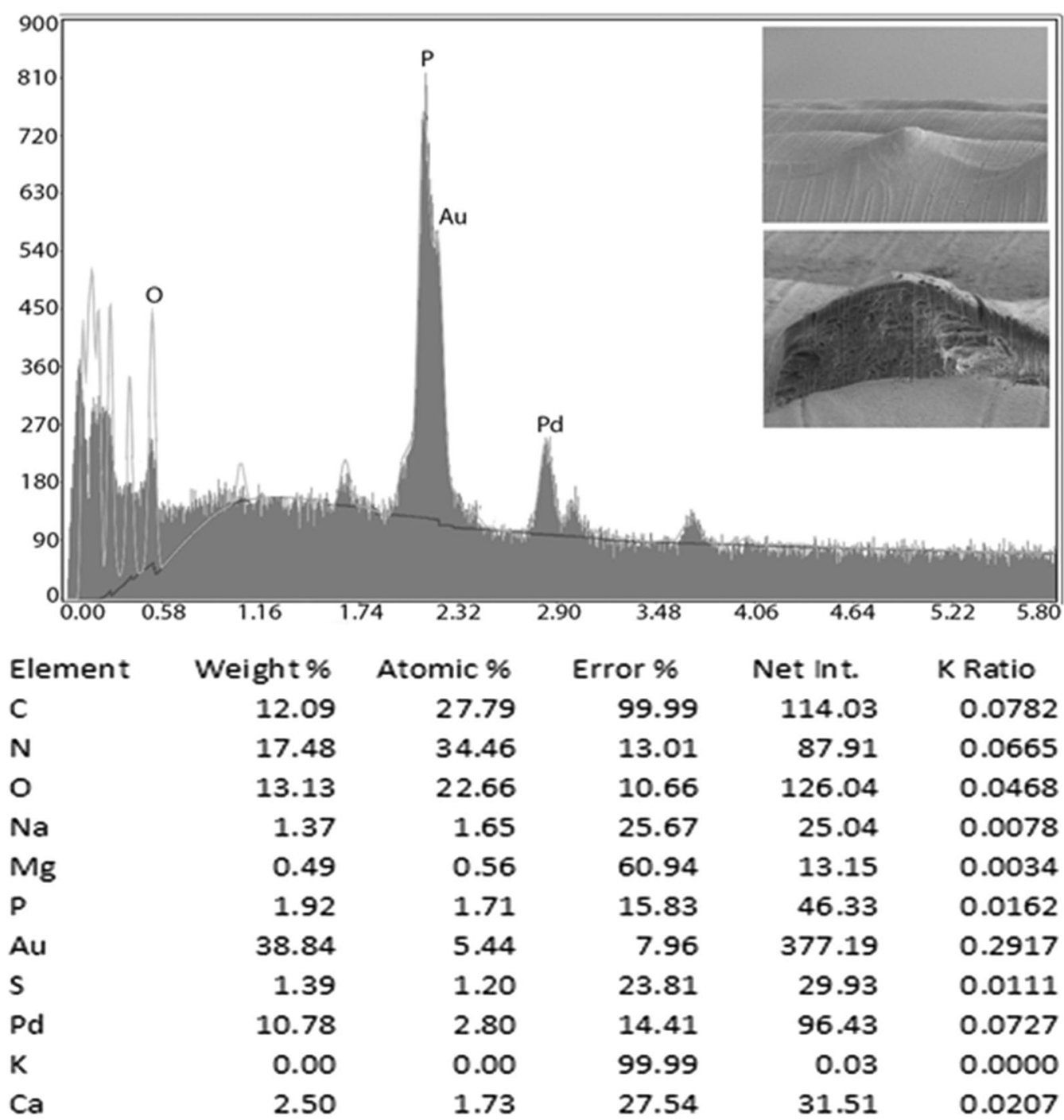

Fig. 7 Energy-dispersive $x$-ray spectrum of the male papillae of a Baylisascaris devosi specimen. Insert: SEM of a gallium cut male papillae

gene analyses, there is $100 \%$ similarity between $B$. devosi obtained in this study and the isolates collected from fisher in Canada and sable in Russia. Also based on ITSrDNA, our sequence has $100 \%$ and $99.8 \%$ homology with Russian B. devosi from sable and Canadian B. devosi from fisher, respectively. Meanwhile, based on the Cox 1 gene, our sequence illustrated more identity with Russian $B$. devosi (99.2\%) than Canadian B. devosi (98.6\%), which is in agreement with the ITS-rDNA tree. Therefore, considering these genetic markers, our sequence had the greatest similarity with Russian $B$. devosi isolated from sable. Inter-generic differences are noted between $B$. devosi and other members of species of genus Baylisascaris based on partial LSU rDNA, ITS-rDNA and Cox1 genes, being $0.9 \%-3.3 \%, 1.1-5.3 \%$ and $4.2-10.3 \%$, respectively. Due to the high level of divergence in the Cox 1 gene, it is appropriate to consider it for phylogenetic and taxonomic studies of genus Baylisascaris. The results of some studies confirmed that mitochondrial genes are suitable markers for phylogenetic relationships and evolutionary biological aspects within the genus Baylisascaris [24, 26, 27].

The reconstructed phylogenetic analysis based on LSU rDNA, ITS-rDNA and Cox1 genes illustrated two main well-supported Baylisascaris clades. Within clade 1, the geographic isolates of $B$. devosi along with $B$. columnaris and $B$. procyonis formed a monophyletic taxon. The isolates of $B$. procyonis and $B$. columnaris in all trees were 


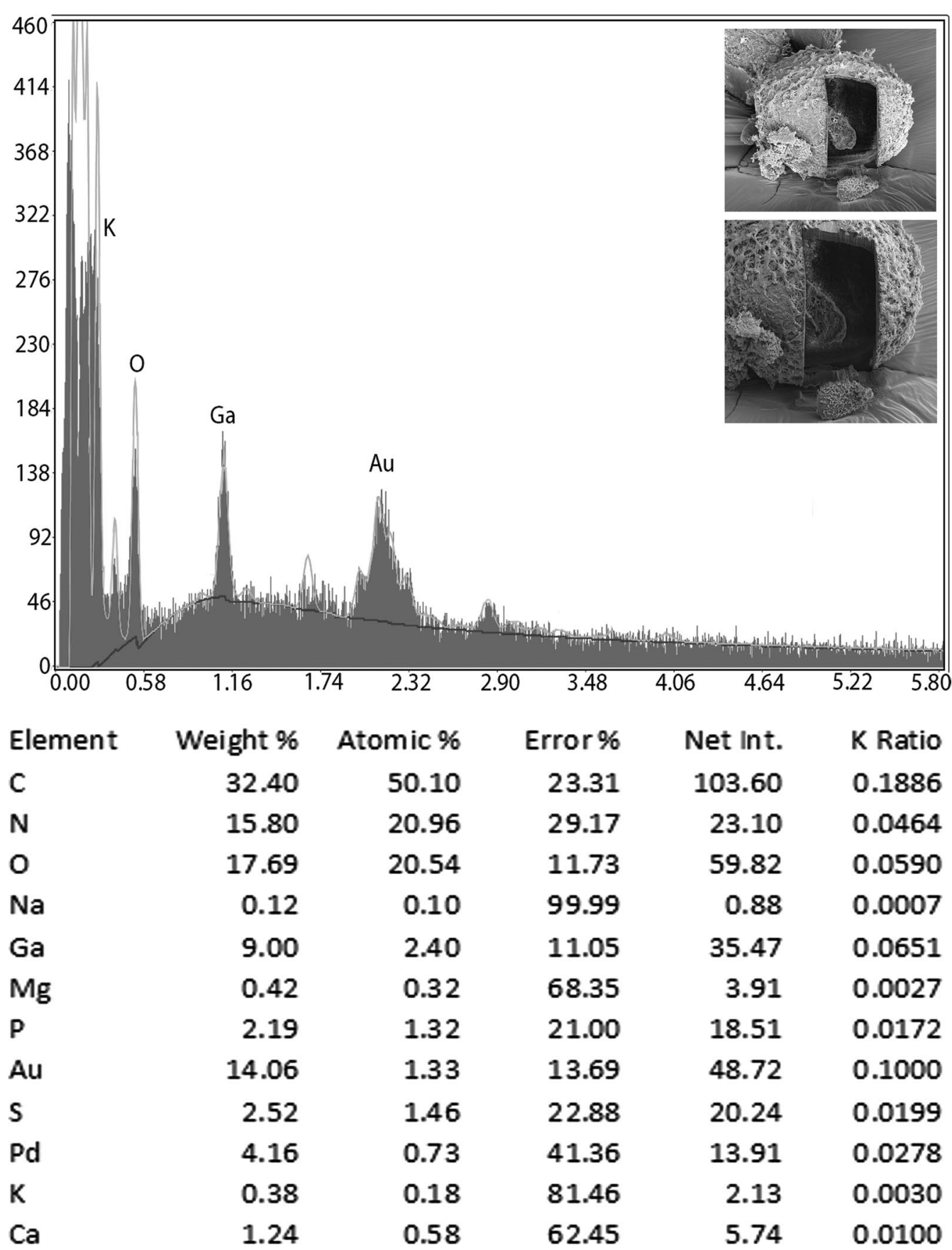

Fig. 8 Energy-dispersive x-ray spectrum of the Baylisascaris devosi egg. Insert: SEM of a cross gallium cut egg

sisters to $B$. devosi with very high or absolute support. Clade 2, which contained the geographic isolates $B$. ailuri, B. schroederi, B. transfuga and B. venezuelensis, was monophyletic and sister group to Clade 1.

Many knowledge gaps still exist in the ecology of $B$. devosi. This nematode lives in the small intestine of carnivorous mammals such as different species of marten and the third-stage larvae present in the cervical and thoracic musculature of paratenic hosts such as rodents and birds $[1,2,5]$. Human is the accidental host of $B$. devosi, and baylisascariasis in human can be caused by this nematode, but the clinical diagnosis of the disease is based on the serological tests, and these tests cannot discriminate among Baylisascaris species [24, 28]. Until now, none of 


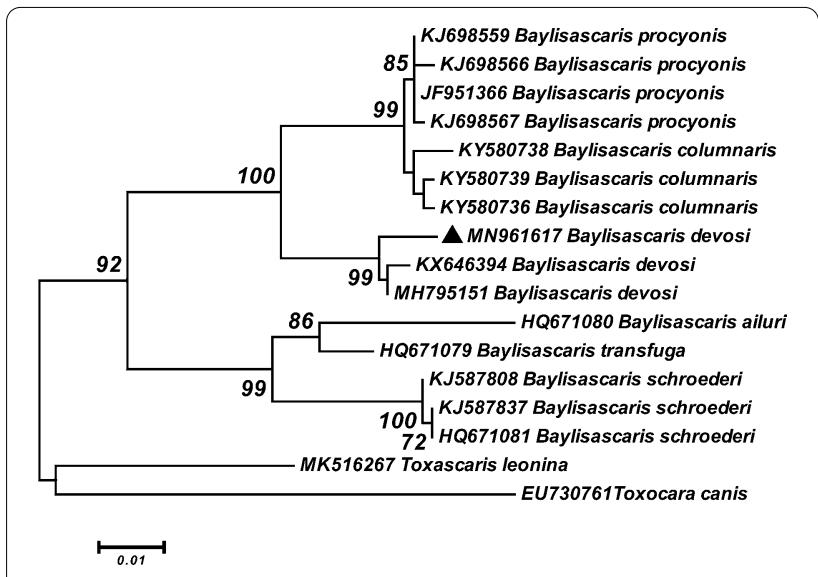

Fig. 9 Phylogenetic analysis of the Cox1 sequence of $B$. devosi isolate obtained in this study (black upward-pointing triangle) and reference sequences retrieved from GenBank. The tree was constructed using the maximum likelihood method and the Tamura three-parameter model in MEGA6 software. Bootstrap values $<70$ are omitted. Toxocara canis and Toxascaris leonina sequences were used as outgroup

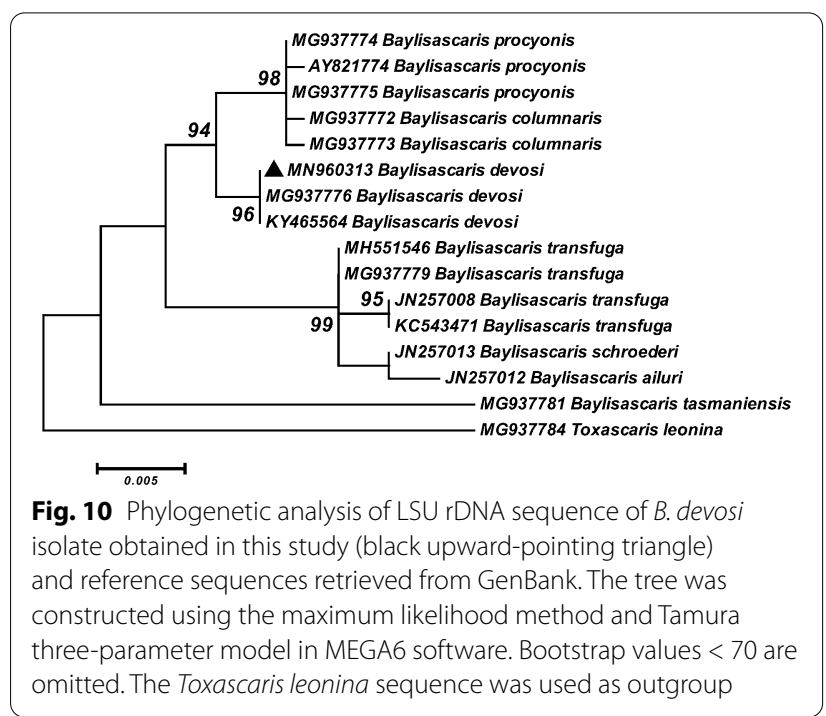

the Baylisascaris species have been reported from Iran, and to our knowledge this study also is the first report of $B$. devosi isolated from the Pine marten. Pine marten is the rarest of mammalian carnivore species in Iran. Baradarani et al. reported five new specimens of Pine marten from the Mazandaran and Golestan provinces within the Caspian region of Iran [29].

\section{Conclusions}

In this study, to our knowledge for the first time, the occurrence of $B$. devosi infection is reported in Pine marten. Metal analysis distinguished high levels of

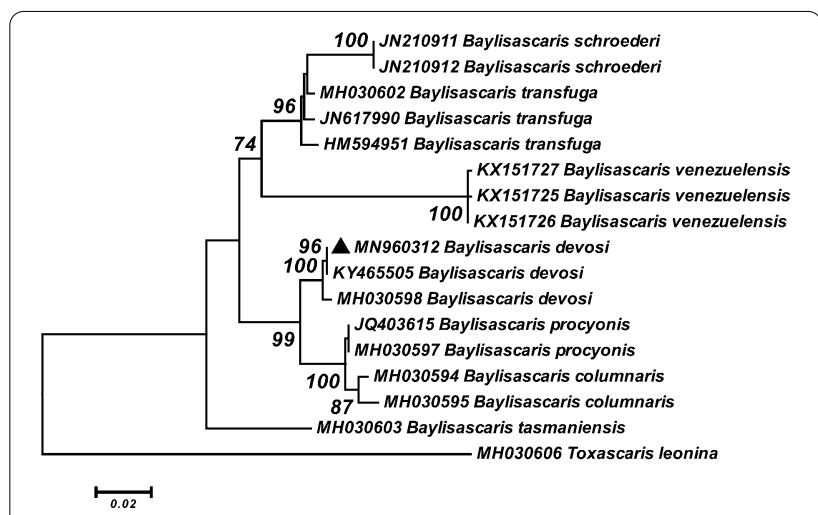

Fig. 11 Phylogenetic analysis of the ITS sequence of B. devosi isolate obtained in this study (black upward-pointing triangle) and reference sequences retrieved from GenBank. The tree was constructed using the maximum likelihood method and Tamura three-parameter model in MEGA6 software. Bootstrap values $<70$ are omitted. The Toxascaris leonina sequence was used as outgroup

phosphorus, calcium and sulfur in male spike and mouth denticle structures. Molecular analysis of partial LSU rDNA, ITS-rDNA and Cox1 genes showed that these three regions are suitable molecular markers for inferring phylogenetic relationships of Baylisascaris species. Furthermore, the high divergence of Cox1 among between Baylisascaris species indicates that Cox 1 could be used for the identification of species and molecular phylogenetic studies.

\section{Abbreviations}

Cox1: Cyclooxygenase 1; LSU rDNA: Large subunit ribosomal DNA; ITS-rDNA: Internal transcribed spacer ribosomal DNA; PCR: Polymerase chain reaction; EDAX: Energy dispersive x-ray analysis; SEM: Scanning electron microscopy.

\section{Acknowledgements}

We thank Madison Laurence, Bean Museum (BYU), for expert help in the preparation and organization of plates and figures and Michael Standing, Electron Optics Laboratory (BYU), for his technical help and expertise. The authors thank Prof. Eshrat Beigom Kia from the Department of Medical Parasitology and Mycology, School of Public Health, Tehran University of Medical Sciences, Iran, for her valuable advice. The authors also thank Mr. Sadegh Sabahi for his kind assistance.

\section{Authors' contributions}

MS designed the study and collected of the samples. MS carried out the molecular and phylogenetic analysis. RAH performed the SEM, ion sectioning and energy dispersive $x$-ray analysis. MS, FM and RAH assisted with manuscript writing. All authors read and approved the final manuscript.

\section{Funding}

Not applicable.

\section{Availability of data and materials}

All data generated or analyzed during the present study are included in this published article.

\section{Ethics approval and consent to participate}

The study was approved by the Ethics Committee of Guilan University of Medical Sciences, Iran (IR.GUMS.REC.1398.539). 


\section{Consent for publication}

Not applicable.

\section{Competing interests}

The authors declare that they have no competing interests.

\section{Author details}

${ }^{1}$ Department of Medical Parasitology and Mycology, School of Medicine, Guilan University of Medical Sciences, Rasht, Iran. ${ }^{2}$ Department of Biology, Brigham Young University, 1114 MLBM, Provo, Utah 84602, USA. ${ }^{3}$ Department of Parasitology and Mycology, School of Medicine, Shiraz University of Medical Sciences, Shiraz, Iran.

\section{Received: 7 September 2020 Accepted: 1 December 2020}

Published online: 08 January 2021

\section{References}

1. Sapp SG, Gupta P, Martin MK, Murray MH, Niedringhaus KD, Pfaff MA, et al. Beyond the raccoon roundworm: the natural history of non-raccoon Baylisascaris species in the New World. Int J Parasitol Parasites Wildl. 2017;6:85-99.

2. Sprent J. On the life history of Ascaris devosi and its development in the white mouse and the domestic ferret. Parasitology. 1953;42:244-58.

3. Kazacos K. Baylisascaris larva migrans: US Geological Survey circular 1412. Reston (VA): US Geological Survey; 2016.

4. French SK, Pearl DL, Peregrine AS, Jardine CM. Baylisascaris procyonis infection in raccoons: a review of demographic and environmental factors influencing parasite carriage. Vet Parasitol Reg Stud Reports. 2019;16:100275.

5. Sprent J. On an ascaris parasite of the fisher and marten Ascaris devosi sp. nov. Proc Helminthol Soc Wash. 1952;19:27-37.

6. Kontrimavichus V. Helminth fauna of Mustelidae in the Far East. Tr Gelmintol Lab. 1963:13:26-47.

7. Hoberg EP, Aubry KB, Brittell JD. Helminth parasitism in martens (Martes americana) and ermines (Mustela erminea) from Washington, with comments on the distribution of Trichinella spiralis. J Wildl Dis. 1990;26:447-52.

8. Nemeth C, Tannis M. In: Wacky Work on Worms in Wolverines. The identification of Baylisascaris devosi parasite. http://words.usask.ca/wcvm/files /2014/07/wolverine-research-poster.pdf. 2014

9. Tranbenkova NA, Spiridonov SE. Molecular characterization of Baylisascaris devosi Sprent, 1952 (Ascaridoidea, Nematoda) from Kamchatka sables. Helminthologia. 2017;54:105-12.

10. Lee RE. Scanning electron microscopy and x-ray microanalysis. Englewood Cliffs, New Jersey: Prentice Hall; 1992. p. 458.

11. Folmer $\mathrm{O}$, Black M, Hoeh W, Lutz R, Vrijenhoek R. DNA primers for amplification of mitochondrial cytochrome c oxidase subunit I from diverse metazoan invertebrates. Mol Mar Biol Biotechnol. 1994;3:294-9.

12. Nadler SA, D'Amelio S, Fagerholm HP, Berland B, Paggi L. Phylogenetic relationships among species of Contracaecum Railliet \& Henry, 1912 and Phocascaris Høst, 1932 (Nematoda:Ascaridoidea) based on nuclear rDNA sequence data. Parasitology. 2000;12:455-63.

13. Vrain T, Wakarchuk D, Levesque A, Hamilton R. Intraspecific rDNA restriction fragment length polymorphism in the Xiphinema americanum group. Fundam Appl Nematol. 1992;15:563-73.

14. Joyce SA, Reid A, Driver F, Curran J, Burnell AM, Ehlers RU, et al. Application of polymerase chain reaction (PCR) methods to the identification of entomopathogenic nematodes. In: Burnell AM, Ehlers RU, Massob JP, editors., et al., Genetics of entomopathogenic nematodes-bacterium complexes. European Commission: Luxembourg; 1994. p. 178-87.

15. Sprent J. Notes on Ascaris and Toxascaris, with a definition of Baylisascaris gen. nov. Parasitology. 1968;58:185-98.

16. Heckmann RA, Amin OM, El-Naggar AM. Micropores of Acanthocephala, a scanning electron microscopy study. Sci Parasitol. 2013;14:105-13.

17. Heckmann RA, Amin OM, Radwan N, Standing MD, Eggett DL, El Naggar AM. Fine structure and energy dispersive X-ray analysis (EDXA) of the proboscis hooks of Rhadinorynchus ornatus, Van Cleave 1918 (Rhadinorynchidae: Acanthocephala). Sci Parasitol. 2012;13:37-43.

18. Heckmann RA, Amin OM, Standing MD. Chemical analysis of metals in acanthocephalans using energy dispersive $X$-ray analysis (EDXA) in conjunction with a scanning electron microscope (SEM). Comp Parasitol. 2007;74:388-91.

19. Heckmann RA, Van Ha N, El Naggar AM. Electron Optics Study (SEM, EDXA) of Diplozoon paradoxum (Nordman, 1832) (Diplozoidae, Trematoda) from the common carp, Cyprinus carpio L. (Cyprinadae, Osteoichthyes) in Vietnam with comments on potential host fish. Sci Parasitol. 2012;13:109-17.

20. Amin OM, Heckmann RA, Sharifdini M, Albayati NY. Moniliformis cryptosaudi n. sp. (Acanthocephala: Moniliformidae) from the long-eared hedgehog Hemiechinus auritus (Gmelin)(Erinaceidae) in Iraq; a case of incipient cryptic speciation related to M saudi in Saudi Arabia. Acta Parasitol. 2019;64:195-204.

21. Amin OM, Sharifdini M, Heckmann R, Ha NV. On three species of Neoechinorhynchus (Acanthocephala: Neoechinorhynchidae) from the Pacific Ocean off Vietnam with the molecular description of Neoechinorhynchus (N.) dimorphospinus Amin and Sey, 1996. J Parasitol. 2019;105:606-18.

22. Amin OM, Sharifdini M, Heckmann RA, Rubtsova N, Chine HJ. On the Neoechinorhynchus agilis (Acanthocephala: Neoechinorhynchidae) complex, with a description of Neoechinorhynchus ponticus n. sp. from Chelon auratus in the Black Sea. Parasite. 2020;27:48

23. Amin OM, Sharifdini M, Heckmann RA, Zarean M. New perspectives on Nephridiacanthus major (Acanthocephala: Oligacanthorhynchidae) collected from hedgehogs in Iran. J Helminthol. 2020;94:133.

24. Camp LE, Radke MR, Shihabi DM, Pagan C, Yang G, Nadler SA. Molecular phylogenetics and species-level systematics of Baylisascaris. Int J Parasitol Parasites Wildl. 2018;7:450-62.

25. Yang G. Molecular characterization and phylogenetic analysis of ascarid nematodes from twenty-one species of captive wild mammals based on mitochondrial and nuclear sequences. Parasitology. 2012;139:1329-38.

26. Xie Y, Zhang Z, Niu L, Wang Q, Wang C, Lan J, et al. The mitochondrial genome of Baylisascaris procyonis. PLoS ONE. 2011;6:27066.

27. Xie Y, Zhang Z, Wang C, Lan J, Li Y, Chen Z, et al. Complete mitochondrial genomes of Baylisascaris schroederi, Baylisascaris ailuri and Baylisascaris transfuga from giant panda, red panda and polar bear. Gene. 2011;482:59-67.

28. Graeff-Teixeira C, Morassutti AL, Kazacos KR. Update on baylisascariasis, a highly pathogenic zoonotic infection. Clin Microbiol Rev. 2016;29:375-99.

29. Baradarani K, Moqanaki EM, Adibi MA, Mousavi A. New locality records of pine marten Martes martes from Iran. Small Carniv Conserv. 2016;54:4-8.

30. Nadler SA, D'Amelio S, Dailey MD, Paggi L, Siu S, Sakanari JA. Molecular phylogenetics and diagnosis of Anisakis, Pseudoterranova, and Contracaecum from northern Pacific marine mammals. Parasitology. 2005;91:1413-29.

31. Davidson RK, Oines O, Hamnes IS, Schulze JE. Illegal wild life imports more than just animals-Baylisascaris procyonis in raccoons (Procyon lotor) in Norway. J Wildl Dis. 2013;49:986-90.

32. Hoberg EP, Burek-Huntington K, Beckmen K, Camp LE, Nadler SA. Transuterine infection by Baylisascaris transfuga: neurological migration and fatal debilitation in sibling moose calves (Alces alces gigas) from Alaska. Int J Parasitol Parasites Wildl. 2018;7:280-8.

33. Choi Y, Mason S, Ahlborn M, Zscheile B, Wilson E. Partial molecular characterization of the mitochondrial genome of Baylisascaris columnaris and prevalence of infection in a wild population of Striped skunks. Int J Parasitol Parasites Wildl. 2017;6:70-5.

34. Franssen F, Xie K, Sprong H, van der Giessen J. Molecular analysis of Baylisascaris columnaris revealed mitochondrial and nuclear polymorphisms. Parasit Vectors. 2013:6:124.

35. Testini G, Papini R, Lia R, Parisi A, Dantas-Torres F, Traversa D, et al. New insights into the morphology, molecular characterization and identification of Baylisascaris transfuga (Ascaridida, Ascarididae). Vet Parasitol. 2011;175:97-102

36. Xie Y, Zhou X, Zhang Z, Wang C, Sun Y, Liu T, et al. Absence of genetic structure in Baylisascaris schroederi populations, a giant panda parasite, determined by mitochondrial sequencing. Parasit Vectors. 2014;7:1-12.

37. Mata AP, Pérez HG, Parra JG. Morphological molecular description of Baylisascaris venezuelensis, n. sp. from a natural infection in the South American spectacled bear Tremarctos ornatus Cuvier, 1825 in Venezuela. Neotrop Helminthol. 2016;10:85-103.

\section{Publisher's Note}

Springer Nature remains neutral with regard to jurisdictional claims in published maps and institutional affiliations. 